\title{
ADAPTING THE SURVEY OF ATTITUDES TOWARDS STATISTICS (SATS-36) FOR ESTONIAN SECONDARY SCHOOL STUDENTS
}

\author{
CARITA HOMMIK \\ University of Tartu \\ caritahommik@gmail.com \\ PIRET LUIK \\ University of Tartu \\ piret.luik@ut.ee
}

\begin{abstract}
The purpose of this study is to adapt the Survey of Attitudes Towards Statistics (SATS-36) for Estonian secondary school students in order to develop a valid instrument to measure students' attitudes within the Estonian educational context. The SATS-36 was administered to Estonian-speaking secondary school students before their compulsory statistics course. Because the fit indices for confirmatory factor analysis did not indicate a good fit, an exploratory factor analysis was conducted to find a new model. It validated a four-factor structure of the scale, excluding nine items. Good indices for both reliability and validity were obtained. Trends in secondary school students' attitudes were also examined to investigate the effects of gender and gender combined with the level of education. Results showed that students tended to feel rather positively about statistics at the beginning of the course. All four factors displayed differences between boys and girls. Comparison of lower and upper secondary level students showed that students from the upper secondary level value statistics more highly. The authors recommend SATS with some small proposed changes to make it even more suitable for the secondary level.
\end{abstract}

Keywords: Statistics education research, Secondary school, Statistics, Attitudes, SATS

\section{INTRODUCTION}

In today's professional environment, statistics is increasingly important, playing a vital role in many fields (e.g., medicine, economics, engineering, natural and social sciences) where statistical techniques are highly valued (Wackerly, Mendenhall, \& Scheaffer, 2007). In line with that, students in different disciplines take obligatory statistics courses during their higher education studies. Statistics is often also offered in secondary education. Unfortunately, many students fail to recognize its importance (Peters, Smith, Middledorp, Karpin, Sin, \& Kilgore, 2013). In order for students to succeed in the course and be prepared to use statistics later, they need to believe that they can understand statistics and that it is valuable to them (Emmioglu \& Capa-Aydin, 2012; Schau 2003). However, acquiring statistical skills and knowledge poses significant challenges for many students; a statistics course is challenging because it is abstract and requires logical reasoning, critical thinking, and the skills of interpretation and drawing

Statistics Education Research Journal, 16(1), 228-239, http://iase-web.org/Publications.php? $p=$ SERJ

(C) International Association for Statistical Education (IASE/ISI), May, 2017 
conclusions (Peters et al.). Because of these challenges, many students perceive statistics as difficult and uninteresting (Sotos, VanHoof, Van den Noortgate, \& Onghena, 2007).

Previous research has shown that understanding attitudes is very important to understanding student achievement in general. Students' beliefs about their ability and expectations of success are the most accurate way to predict their achievements in mathematics (Wigfield \& Eccles, 2000). The concept of attitude has been at the center of social and behavioral sciences since 1935. It is a multi-component construct and difficult to understand. The term is often used to understand and predict people's reaction to an object or change and to explore how behavior can be influenced (Eagly \& Chaiken, 2007) for it is easier to measure attitude than behavior (Geller, 1996). Attitudes "refer to an individual's propensity to evaluate a particular entity with some degree of favorability or unfavorability" (Eagly \& Chaiken, p. 583) The nature of attitudes could be described in terms of three components: cognitive, affective, and behavioral (Rosenberg \& Hovland, 1960, cited in Bagozzi \& Burnkrant, 1979). The cognitive component of attitudes involves knowledge, belief, opinion, and information that anyone has about the object of attitudes; the affective component refers to likes/dislikes or expectations; and the action component describes the expectations of future conduct (Bagozzi \& Burnkrant).

Several surveys have been developed to measure students' attitudes towards statistics. For instance, the Statistics Attitude Survey (SAS) by Roberts and Bilderback (1980) and the Attitudes Toward Statistics (ATS) survey by Wise (1985) are widely used. SATS-28 and its expanded version SATS-36 (28 and 36 questions, respectively) (Survey of Attitudes Towards Statistics; Schau, Stevens, Dauphinee, \& Vecchio, 1995; Schau, 2003) are also used in several countries. For example, SATS-28 has been used in Italy (Chiesi \& Primi, 2009), SATS-36 in Serbia (Stanisavljevic et al., 2014), the Netherlands (Tempelaar, van der Loeff, \& Gijselaers, 2007; VanHoof, Kuppens, Castro Sotos, Verschaffel, \& Onghena, 2011), and Russia (Khavenson, Orel, \& Tryakshina, 2012). Originally, the survey was developed with a four-component structure that included Affect, Cognitive Competence, Value, and Difficulty (SATS-28) (Schau et al.). Later, Schau developed it into SATS-36 by adding two more components: Effort and Interest. These components are discussed further in the methods section. Schau developed her surveys to improve upon the issues identified in previous surveys (Ramirez, Schau, \& Emmioglu, 2012) and, thus, this study uses SATS-36 (copyright held by Candace Schau). The decision to choose this survey is also supported by a systematic review (Nolan, Beran, \& Hecker, 2012) that suggests that SATS-36 appears to have the strongest evidence of construct validity and internal consistency.

There is considerable research on students' attitudes towards statistics, but it is limited to post-secondary school students (e.g., Khavenson et al., 2012, Chiesi \& Primi, 2009, Stanisavljevic et al., 2014, and Schield \& Schield, 2008). In their meta-analysis, Emmioğlu \& Capa-Aydin (2012) looked at 17 studies from eight countries between 1998 and 2011 that used SATS-28 in measuring students' attitudes towards statistics and their statistics achievement. The participants in all the studies were post-secondary school students. Because statistics education starts earlier, it is also important to measure the attitudes of lower level students. This study aims to fill this gap and assess secondary school students' attitudes towards statistics.

The aim of this paper is to establish whether the data collected on Estonian secondary school students match the original structure of the six components of SATS-36 using confirmatory factor analysis. If the fit is not good, the aim is to find an acceptable model for the data. 


\section{METHOD}

\subsection{CONTEXT OF THE RESEARCH}

Statistics has been part of the mathematics curriculum in Estonia for decades. Currently, a small section of statistics is taught in the $7^{\text {th }}$ grade (age 13-14), and there is another more thorough course (35 lessons of 45 minutes) in the $10^{\text {th }}$ grade (age 16-17). These are the recommended grades to teach statistics in, but teachers have the final say and they often teach statistics in grades 8 and 11 instead. Estonia is currently rethinking its statistics education to account for the fact that, in real life, computers are an important part of doing statistics. Unfortunately, they are not used habitually to teach statistics (at least not in the secondary school). To change that, a new secondary school statistics course has been designed with an emphasis on computer-based materials and contextbased learning. To examine the effect of this new instructional intervention on students' attitudes, an efficient instrument was needed. This paper reports on the validation process to establish an instrument to measure students' attitudes that could then be used as part of other studies on impact of curricula interventions in Estonia.

\subsection{PARTICIPANTS}

The data were gathered in the spring and autumn of 2014. A total of 1357 students answered the SATS. The students were from 35 schools and taught by 54 teachers. The schools are a representative sample of Estonian schools in that they cover Estonia geographically, offer a cross-section of the lower and upper grades (grades 7-9 (ages 1316) and 10-12 (ages 16-18), respectively) and are representative in terms of size, including schools with only lower secondary level as well as schools with both lower and upper levels. At the time, Estonia had 460 schools with secondary levels. Table 1 presents the description of the sample.

Table 1

Description of the Sample

\begin{tabular}{llll}
\hline & Lower secondary & Upper secondary & Total \\
\hline Female & $349(57 \%)$ & $441(59 \%)$ & $790(58 \%)$ \\
\hline Male & $261(43 \%)$ & $306(41 \%)$ & $567(42 \%)$ \\
\hline Total & $610(100 \%)$ & $747(100 \%)$ & $1357(100 \%)$ \\
\hline
\end{tabular}

\subsection{DATA COLLECTION INSTRUMENT - SATS}

SATS includes 36 items on a Likert-type scale of seven. Each of the 36 items were presented to the students before taking a statistics course, and they had to choose their level of agreement on a scale of 7, where 1 means "Strongly disagree" and 7 means "Strongly agree". All the items are written in the future (e.g., "I plan to complete all of my statistics assignments").

Following Schau (2003), the items are grouped into six attitude components:

1. Affect - students' feelings concerning statistics.

2. Cognitive Competence - students' attitudes about their intellectual knowledge and skills in terms of statistics. 
3. Value - students' attitudes about the usefulness, relevance, and value of statistics in personal and professional life.

4. Difficulty - students' attitudes about the difficulty of statistics as a subject.

5. Interest - students' level of individual interest in statistics.

6. Effort - the amount of work required from the student to learn statistics.

In order to adapt SATS-36 for Estonia, the stages of cross-cultural adaption were used as a model (Beaton, Bombardier, Guillemin, \& Frerraz, 2000). First, the questionnaire was translated from English into Estonian by the first author of this paper with the help of an expert with a Master's degree in English language. After this, another person translated the text back into English. Then, the two English versions were compared to ensure that the meaning of the items remained the same. Finally, the questionnaire was administered to three classes of students who were instructed to write down suggestions when filling out the instrument. As a result, some words were replaced or specified (e.g., the words "conceptual" and "technical" were too difficult for the students to understand).

\subsection{DATA ANALYSIS}

For reliability and validity, Cronbach's alpha and confirmatory factor analysis (CFA) were used. Because the model fit indices for Schau's SATS-36 were not good enough to produce an acceptable model (Table 2), exploratory factor analysis was conducted to find a new model. For a better interpretation of the results, rotation method Varimax was used. After that, the model was evaluated using CFA. To evaluate the model fit, three types of goodness-of-fit indices were used: 1) absolute fit indices: Goodness of Fit Index (GFI), Root Mean Square Residual (RMR), Root Mean Square Error of Approximation (RMSEA); 2) Parsimonious fit index: Parsimonious Goodness of Fit (PGFI); 3) relative fit index: Bentler and Bonnet's NFI (Normed Fit Index). The Chi-square test was not used because a non-significant chi-square is rarely obtained with large sample sizes (which was the case in the present study) (Bentler \& Bonett, 1980). It has been suggested (Byrne, 1994; Stieger, 1990) that a value of GFI greater than .90, a value of RMR and RMSEA less than .05 , a value of PGFI greater than .50, and a value of NFI greater than .90 , are indications of a good fit. Also, values of RMR and RMSEA between .05 and .08 still show a reasonable fit of the model (Browne \& Cudeck, 1993). The method used was maximum likelihood estimation. Factor analysis was conducted using SAS 9.2 software.

In analyzing students' attitudes towards statistics, linear mixed models were used with the help of SPSS Statistics 23 software. Assuming that there might be an effect on the teacher and that students in each class are somewhat similar, teacher effect was included as a random effect. The Bonferroni correction was used on $p$-values to counteract the problem of multiple comparisons.

\section{RESULTS}

\subsection{THE NEW MODEL}

CFA results indicated that our data did not fit well with Schau's theoretical model. None of the goodness-of-fit indices listed above were acceptable for a good model (Table 2). Based on the answers of the SATS from 1357 students, an exploratory factor analysis was conducted. Item numbers used here and henceforth are the same as in Schau's SATS36. Due to technical problems, answers to item 27 ("I plan to attend every statistics class lesson") were missing from 534 students. Therefore, it was excluded. However, because it is mandatory to attend classes at the secondary school in Estonia, it can be assumed that 
most, if not all, of the students did plan to attend all the classes. Hence, the item itself is redundant. In addition to item 27, eight more items were excluded: items 22, 30, and 35 due to low factor loadings (less than .40); items 6 and 32 due to high standardized residuals. To further improve fit indices, items 15, 24, and 34 were also excluded due to fairly low factor loadings (.41, .41 and .40 , respectively). CFA was conducted again from the start each time an item was excluded. The final fit indices are presented in Table 2.

Table 2

Goodness of Fit Indices for Schau's SATS-36 Six-factor Model and for our Modified Four-factor Model

\begin{tabular}{lll}
\hline Fit index & SATS-36 six-factor model & Modified four-factor model \\
\hline GFI & .714 & .883 \\
RMR & .138 & .073 \\
RMSEA & .087 & .069 \\
PGFI & .665 & .802 \\
Bentler\&Bonnet's NFI & .674 & .851 \\
\hline
\end{tabular}

Because three fit statistics indicate acceptable fit and two statistics are close to indicating acceptable fit, the CFA analysis has confirmed the factor structure (similarly concluded by Suhr, 2006). In addition, fit indices for the modified four-factor model show progress compared to the original six-factor model and, thus, the four-factor model should be accepted. The new model includes four attitude components instead of six, where Affect, Cognitive Competence, and Difficulty are in the same factor (titled Competence). The internal consistency constant Cronbach's alpha is .904 for the Estonian Secondary SATS. It suggests that the survey has a satisfactory reliability in assessing students' attitudes towards statistics. All Cronbach's alpha values in different components exceeded .80 (Table 3 ).

Table 3

Cronbach's Alpha Values for Estonian Secondary SATS in Each Component

\begin{tabular}{ll}
\hline Component & Estonian Secondary SATS \\
\hline Overall & .904 \\
Interest & .873 \\
Competence & .853 \\
Value & .819 \\
Effort & .812 \\
\hline
\end{tabular}

Table 4 lists the individual 27 items from the Estonian Secondary SATS grouped into the four attitude components. The items that were excluded are:

1. Statistics formulas are easy to understand (item 6).

2. I will get frustrated going over statistics tests in class (item 15).

3. Statistics is a subject quickly learned by most people (item 22).

4. Learning statistics requires a great deal of discipline (item 24).

5. I plan to attend every statistics class session (item 27).

6. Statistics involves massive computations (item 30).

7. I will understand statistics equations (item 32).

8. Statistics is highly technical (item 34).

9. I will find it difficult to understand statistical concepts (item 35). 
Table 4

Factor Structure and Factor Loadings for the Estonian Secondary SATS

\begin{tabular}{|c|c|c|}
\hline Factor & Items the factor contains & Factor loading \\
\hline \multirow[t]{8}{*}{ Interest } & I will like statistics.* & .53 \\
\hline & $\begin{array}{l}\text { Statistics should be a required part of my professional } \\
\text { training.** }\end{array}$ & .52 \\
\hline & $\begin{array}{l}\text { I am interested in being able to communicate statistical } \\
\text { information to others. }\end{array}$ & .52 \\
\hline & I will enjoy taking statistics courses.* & .62 \\
\hline & I am interested in using statistics. & .70 \\
\hline & I am interested in understanding statistical information. & .62 \\
\hline & I am interested in learning statistics. & .66 \\
\hline & I can learn statistics. & .58 \\
\hline \multirow[t]{8}{*}{ Competence } & I will feel insecure when I have to do statistics problems. & .64 \\
\hline & $\begin{array}{l}\text { I will have trouble understanding statistics because of } \\
\text { how I think. }\end{array}$ & .66 \\
\hline & Statistics is a complicated subject. & .61 \\
\hline & $\begin{array}{l}\text { I will have no idea of what's going on in this statistics } \\
\text { course. }\end{array}$ & .64 \\
\hline & I will be under stress during statistics class. & .66 \\
\hline & I will make a lot of math errors in statistics. & .62 \\
\hline & I am scared by statistics. & .68 \\
\hline & $\begin{array}{l}\text { Most people have to learn a new way of thinking to do } \\
\text { statistics. }\end{array}$ & .46 \\
\hline \multirow[t]{8}{*}{ Value } & Statistics is worthless. & .47 \\
\hline & Statistical skills will make me more employable. & .42 \\
\hline & Statistics is not useful to the typical professional. & .61 \\
\hline & $\begin{array}{l}\text { Statistical thinking is not applicable in my life outside my } \\
\text { job. }\end{array}$ & .65 \\
\hline & I use statistics in my everyday life. & .43 \\
\hline & $\begin{array}{l}\text { Statistics conclusions are rarely presented in everyday } \\
\text { life. }\end{array}$ & .57 \\
\hline & I will have no application for statistics in my profession. & .64 \\
\hline & Statistics is irrelevant in my life. & .68 \\
\hline \multirow[t]{3}{*}{ Effort } & I plan to complete all of my statistics assignments. & .76 \\
\hline & I plan to work hard in my statistics course. & .80 \\
\hline & I plan to study hard for every statistics test. & .67 \\
\hline
\end{tabular}

*In Schau's model, these items belonged into the factor "Affect".

**In Schau's model, this item belonged into the factor "Value".

\subsection{STUDENTS' ATTITUDES TOWARDS STATISTICS}

Students at the lower and upper secondary levels feel quite similarly towards statistics (Table 5). The only difference is in how they value statistics. This is the only statistical difference between the two levels: students from the upper secondary level value statistics more $(p=0.012)$. All the mean scores are above 4 (neutral). This means that, at the beginning of the statistics course, students' attitudes were rather positive. They feel most positively about their effort, that is, about how much work they plan to do to learn statistics. 
Table 5

Estonian Secondary SATS Results at the Lower and Upper Secondary Levels

\begin{tabular}{|c|c|c|c|c|c|c|c|c|c|c|}
\hline \multirow[t]{2}{*}{ Factor } & \multicolumn{3}{|c|}{ Lower secondary } & \multicolumn{3}{|c|}{ Upper secondary } & \multirow[t]{2}{*}{ Df } & \multirow[t]{2}{*}{$\mathrm{F}$} & \multirow[t]{2}{*}{ Sig. } & \multirow{2}{*}{$\begin{array}{l}\text { Sig. } \\
\text { corrected }\end{array}$} \\
\hline & $\mathrm{N}$ & Mean & $\begin{array}{l}\text { Std. } \\
\text { Error }\end{array}$ & $\mathrm{N}$ & Mean & $\begin{array}{l}\text { Std. } \\
\text { Error }\end{array}$ & & & & \\
\hline \multicolumn{11}{|c|}{ Competence } \\
\hline Overall & 610 & 4.473 & .063 & 747 & 4.521 & .057 & 99.328 & .363 & .548 & 1.000 \\
\hline Male & 261 & 4.608 & .081 & 306 & 4.836 & .075 & & & & \\
\hline Female & 349 & 4.366 & .074 & 441 & 4.302 & .067 & & & & \\
\hline \multicolumn{11}{|l|}{ Value } \\
\hline Overall & 610 & 4.507 & .060 & 747 & 4.733 & .055 & 121.681 & 9.070 & .003 & .012 \\
\hline Male & 261 & 4.501 & .074 & 306 & 4.867 & .068 & & & & \\
\hline Female & 349 & 4.509 & .068 & 441 & 4.638 & .062 & & & & \\
\hline \multicolumn{11}{|l|}{ Interest } \\
\hline Overall & 610 & 4.351 & .071 & 747 & 4.480 & .065 & 126.238 & 2.138 & .146 & .584 \\
\hline Male & 261 & 4.382 & .087 & 306 & 4.596 & .080 & & & & \\
\hline Female & 349 & 4.325 & .080 & 441 & 4.398 & .073 & & & & \\
\hline \multicolumn{11}{|l|}{ Effort } \\
\hline Overall & 610 & 5.297 & .082 & 747 & 5.250 & .075 & 134.664 & 0.219 & .641 & 1.000 \\
\hline Male & 261 & 4.964 & .094 & 306 & 4.986 & .086 & & & & \\
\hline Female & 349 & 5.551 & .087 & 441 & 5.437 & .079 & & & & \\
\hline
\end{tabular}

The effects of gender and school level*gender were also tested. Several statistical differences were found (Table 6). There were differences between genders in all four factors. In the first three factors (Competence, Value and Interest), male students tended to have higher mean scores than female students (Table 5). However, this was not the case in the Effort factor where female students had noticeably higher scores than male students (Table 5).

We also observed that male students from the upper secondary level rated their Competence higher than males from the lower secondary level (Table 5). In Table 5, we can see that students from the upper secondary level value statistics more. However, this statistical difference comes mostly from the male students in the upper secondary level (Table 5).

Table 6

Type III Tests of Fixed Effects

\begin{tabular}{llllll}
\hline Factor & Source & Numerator df & Denominator df & F & Sig. \\
\hline Competence & & & & & \\
& Gender & 1 & 1344.103 & 44.038 & .000 \\
Value & School level*Gender & 1 & 1343.729 & 6.252 & .013 \\
& & 1 & 1336.995 & 5.023 & .025 \\
& Gender & 1 & 1336.672 & 5.744 & .017 \\
Interest & School level* Gender & 1 & & & \\
& & 1 & 1336.353 & 4.944 & .026 \\
& Gender & 1 & & 1.485 & .223 \\
Effort & School level*Gender & 1 & 1334.615 & 71.883 & .000 \\
& Gender & 1 & 1334.311 & 1.262 & .261 \\
\hline
\end{tabular}




\section{DISCUSSION}

\subsection{VALIDATION OF THE SATS}

The goal of this study has been to validate a well-known instrument (SATS-36) to measure students' attitudes towards statistics for secondary school students in Estonia. Our study provided evidence of the appropriateness of a four-factor structure of the SATS. The structure of the SATS has been investigated before, and it has been proposed that Affect, Cognitive Competence and Difficulty could be combined into one factor without losing much information, because the first two are strongly correlated and moderately to strongly correlated with Difficulty (Tempelaar et al., 2007). It has also been discussed that SATS-28 has two underlying factors: (1) the value of statistics, and (2) the different aspects of how a student will perform in the statistics course, which is measured by the items in Affect, Cognitive Competence and Difficulty (Cashin \& Elmore, 2005). These previous studies explain why, in this study, the best fit was achieved when the three components were combined. The six-factor model of SATS-36 has been compared to the four-factor model where the three components are combined into one factor to assess the relative fit of these two models. The conclusion from comparisons has been that "both the six- and four-factor models appropriately describe the observed interrelationships between SATS-36 items" (VanHoof et al., 2011). VanHoof et al. deleted several Difficulty items (22, 34, and 36) due to low factor loadings. In this study, five Difficulty items were deleted in total, two of them also items 22 ("Statistics is a subject quickly learned by most people") and 34 ("Statistics is highly technical"). VanHoof et al. suggest that excluding item 22 might be related to the fact that it refers to how most people perceive statistics, whereas other items are more about students' attitudes towards statistics as such. The other Difficulty items that were excluded in this study are item 6 ("Statistics formulas are easy to understand"), item 24 ("Learning statistics requires a great deal of discipline"), and item 30 ("Statistics involves massive computations"). The reasons for excluding items 6, 30, and 34 might be related to the fact that secondary school students do not distinguish statistics from mathematics generally, at least when it comes to formulas and calculating. For many students, mathematics equals formulas and calculation. Because nine items out of 36 were excluded, further investigation is needed to find out whether it is because the current study is based on secondary school students or because these items are irrelevant for Estonian learners specifically. In addition, adding or replacing items that are more suitable for secondary school students should be considered.

Next to Estonia, several other countries have adapted SATS for their learners (Chiesi \& Primi, 2009; Khavenson et al., 2012; Stanisavljevic et al., 2014). Some of them have used SATS-28 and others SATS-36. Despite some differences from Schau's model (e.g., in Russia, they used seven scales instead of six, and the content of the scales was similar but not equal to the original SATS (Khavenson et al.), their goodness of fit indices have been better than in this study. The main reason for this is probably the fact that all the previous studies on validating SATS were made at the tertiary education level, whereas this study investigated secondary level students. Therefore, in addition to cultural differences, the age difference might also have an effect on how students perceive statistics. However, internal consistency coefficients were in accordance with other validation studies and supported the reliability of each component. 


\subsection{STUDENTS' ATTITUDES TOWARDS STATISTICS}

Differently from the six components in the original SATS-36, there are four components in our model. Cognitive Competence, Affect and Difficulty are in the same factor labelled Competence. The other factors are Value, Interest, and Effort. Means of these components were above neutral (4), implying students' positive attitudes towards statistics. For both lower and upper secondary levels, means of Value and Effort were higher than means of Competence and Interest in the SATS. Because we have three components combined as one, it cannot be compared directly with the results from other studies, but similarities exist. Schau (2003) tested SATS-28 on 580 students and the mean of Value was 4.9, which is higher than in this study (4.6 for the lower secondary level and 4.7 for the upper secondary level). The same mean of Value was also obtained in an Italian study (Chiesi \& Primi, 2009). At the same time, in Serbia, the mean of Value was 4.1 (Stanisavljevic et al., 2014), which is lower than in Estonia. In addition to Value, means of Interest and Effort are also higher in Estonia than in the Serbian study. The means of Competence in this study are also slightly higher than the average of these three components in previous studies (Chiesi \& Primi; Schau; Stanisavljevic et al.).

It can be said that Estonian students scored the same or higher means in attitudes compared to students in other studies. A possible explanation is that secondary school students are less anxious about statistics than post-secondary school students. This might especially be the case because the previous studies involved students mostly from specialties such as psychology and medicine where statistics might be perceived as rather a difficult subject. At the same time, Estonian lower means of Value can be explained with the fact that secondary school students may underestimate the value of and need for statistics in their future life compared to older students. This is also in accordance with the result that students from upper secondary level value statistics more than their lower level counterparts $(p=.012$ being the only significant statistical difference between the two levels).

We also tested the effects of gender, and gender and school level combined. Differences between girls and boys were found in all four factors. Male students tended to have slightly higher scores in factors such as Competence, Value, and Interest whereas girls had higher scores in estimating their Effort. However, in the factors Value and Interest, the difference between genders is present only at the upper secondary level. Previous research has shown that girls are more likely to be concerned about success whereas boys are more likely to be concerned about relevance and pleasure (Vale \& Leder, 2004). Males are also known to be more confident in their skills. Gender differences by school level were obtained from factors Competence and Value. Male students from the upper secondary level were more confident in learning statistics than male students from the lower level. This might be explained by the fact that there are more boys than girls who do not get into the gymnasiums (upper secondary schools) and, therefore, the weaker and less confident boys are left out of the group, resulting in a higher mean value of Competence at the upper secondary level. In terms of Value, students from the upper secondary level appreciate statistics more, especially male students.

In conclusion, Estonian secondary school students have rather positive attitudes towards statistics (all values above 4 (neutral)). The real-life value of statistics is clearer to upper secondary level students than to lower secondary level students. Gender differences are also more present on the upper level than the lower level, where male students had higher mean values. 


\subsection{LIMITATIONS AND RECOMMENDATIONS}

It is necessary to underline some limitations of the study. First, SATS-36 has been previously validated only for post-secondary schools and this probably explains why the model used in this study did not give as good goodness of fit indices as those in previous validation studies. In further studies, the instrument should be modified to better suit secondary school students. For example, researchers could consider changing item 15 ("I will get frustrated going over statistics tests in class") to "I will get frustrated going over my mistakes in statistics tests in class" as students can relate more if the emphasis is on their mistakes not just "going over" (at least in Estonian language the mistakes should be mentioned). Another limitation is that students from the lower and upper secondary levels had had different contact with statistics before answering the questionnaire. Students from the upper secondary level had studied it, to a degree, at the lower secondary level. And so, they had a clearer understanding of the concepts of statistics than the students in lower secondary level for whom the first experience with statistics was about to begin. This does not mean that they did not have any idea about what statistics is but it might not have been as clear.

An important aspect of this study is that students' attitudes towards statistics have not previously been investigated at the secondary schools. It is important that students feel positively about statistics in secondary school already because, during higher education, there are many statistics courses even in the social sciences and humanities, which sometimes comes as a surprise to students (Khavenson et al., 2012). The study shows that, at the beginning of the course, students have rather positive feelings towards statistics.

Our study contributes greatly to the field of researching students' attitudes towards statistics because it uses one widely accepted and used instrument, SATS-36, which is now validated for the Estonian secondary school students based on a fairly large sample. Using the validated instrument, the authors of the study suggest future research on the effect of a statistics course on students' attitudes towards statistics and on the relationships between students' attitudes towards statistics and their statistics achievements.

\section{REFERENCES}

Bagozzi, R. P., \& Burnkrant, R. E. (1979). Attitude measurement and behavior change: a reconsideration of attitude organization and its relationship to behavior. In W.L. Wilkie (Ed.), NA - Advances in Consumer Research, (Vol. 6, pp. 295-302). Ann Arbor, MI: Association for Consumer Research.

Beaton, D. E., Bombardier, C., Guillemin, F., \& Ferraz, M. B. (2000). Guidelines for the process of cross-cultural adaptation of self-report measures. Spine, 25(24), 31863191.

Bentler, P.M., \& Bonett D. G. (1980). Significance tests and goodness of fit in the analysis of covariance structures. Psychological Bulletin, 88(3), 588-606.

Browne, M. W., \& Cudeck, R. (1993). Alternative ways of assessing model fit. Sage Focus Editions, 154, 136-136.

Byrne, B. M. (1994). Structural equation modeling with EQS and EQS/Windows: Basic concepts, applications, and programming. Thousand Oaks, CA: Sage Publications. 
Cashin, S. E., \& Elmore, P. B. (2005). The survey of attitudes toward statistics scale: A construct validity study. Educational and Psychological Measurement, 65(3), 509524.

Chiesi, F., \& Primi, C. (2009). Assessing statistics attitudes among college students: Psychometric properties of the Italian version of the survey of attitudes toward statistics (SATS). Learning and Individual Differences, 19(2), 309-313.

Eagly, A. H., \& Chaiken, S. (2007). The advantages of an inclusive definition of attitude. Social Cognition, 25(5), 582-602.

Emmioglu, E., \& Capa-Aydin, Y. (2012). Attitudes and achievement in statistics: A meta-analysis study. Statistics Education Research Journal, 11(2), 95-102.

Geller, E. S. (1996). Which first - attitude or behavior? Retrieved from http://www.safetyperformance.com/whichfirst-attitudeorbehavior.pdf

Khavenson, T., Orel, E., \& Tryakshina, M. (2012). Adaptation of survey of attitudes towards statistics (SATS 36) for Russian sample. Procedia - Social and Behavioral Sciences, 46, 2126-2129.

Nolan, M. M., Beran, T. A. N. Y. A., \& Hecker, K. G. (2012). Surveys assessing students' attitudes toward statistics: A systematic review of validity and reliability. Statistics Education Research Journal, 11(2), 103-123.

Peters, P., Smith, A., Middledorp, J., Karpin, A., Sin, S., \& Kilgore, A. (2013). Learning essential terms and concepts in statistics and accounting. Higher Education Research \& Development, 33(4), 742-756.

Ramirez, C., Schau, C., \& Emmioglu, E. (2012). The importance of attitudes in statistics education. Statistics Education Research Journal, 11(2), 57-71.

Roberts, D. M., \& Bilderback, E. W. (1980). Reliability and validity of a statistics attitude survey. Educational and Psychological Measurement, 40(1), 235-238.

Schau, C. (2003). Students' attitudes: The "other" important outcome in statistics education. Proceedings of the Joint Statistical Meetings, San Francisco (pp. 36733681).

Schau, C., Stevens, J., Dauphinee, T. L., \& Vecchio, A. D. (1995). The development and validation of the survey of attitudes toward statistics. Educational and Psychological Measurement, 55(5), 868-875.

Schield, M., \& Schield, C. (2008). Student attitudes toward statistics at Augsburg College. Paper presented at the Joint Statistical Meetings-Section on Statistical Education, American Statistical Association. Denver, CO. Retrieved from pdfs.semanticscholar.org/0614/22ab535bd5e4c0e2922ada87088ffbaa6006.pdf

Sotos, A. E. C., Vanhoof, S., Van den Noortgate, W., \& Onghena, P. (2007). Students' misconceptions of statistical inference: A review of the empirical evidence from research on statistics education. Educational Research Review, 2(2), 98-113.

Stanisavljevic, D., Trajkovic, G., Marinkovic, J., Bukumiric, Z., Cirkovic, A., \& Milic, N. (2014). Assessing attitudes towards statistics among medical students: Psychometric properties of the Serbian version of the survey of attitudes towards statistics (SATS). PloS One, 9(11).

Steiger, J. H. (1990). Structural model evaluation and modification: An interval estimation approach. Multivariate Behavioural Research, 25, 173-180.

Suhr, D. D. (2006). Exploratory or confirmatory factor analysis? Proceedings of the thirty-first Annual SAS® Users Group International Conference (pp. 1-17). Cary, NC: SAS Institute Inc.

Tempelaar, D. T., van der Loeff, S. S., \& Gijselaers, W. H. (2007). A structural equation model analyzing the relationship of students' attitudes toward statistics, prior 
reasoning abilities and course performance. Statistics Education Research Journal, 6(2), 78-102.

Vale, C. M., \& Leder, G. C. (2004). Student views of computer-based mathematics in the middle years: Does gender make a difference? Educational Studies in Mathematics, 56(2-3), 287-312.

VanHoof, S., Kuppens, S., Castro Sotos, A. E., Verschaffel, L., \& Onghena, P. (2011). Measuring statistics attitudes: Structure of the survey of attitudes toward statistics. Statistics Education Research Journal, 10(1), 35-51.

Wackerly, D., Mendenhall, W., \& Scheaffer, R. (2007). Mathematical Statistics with Applications. Stamford, CT: Cengage Learning.

Wigfield, A., \& Eccles, J. S. (2000). Expectancy-value theory of achievement motivation. Contemporary Educational Psychology, 25(1), 68-81.

Wise, S. L. (1985). The development and validation of a scale measuring attitudes toward statistics. Educational and Psychological Measurement, 45(2), 401-405.

CARITA HOMMIK

University of Tartu

Faculty of Science and Technology

J. Liivi 2, 50409, Tartu, Estonia 